\title{
Seismic Retrofitting of a RC Building by Adding Steel Plate Shear Walls
}

\author{
M.A. Ismaeil ${ }^{1}$, A.E.Hassaballa ${ }^{3}$ \\ 1 King Khalid University, KSA. On Leave from Sudan University of Science and Technology, Khartoum, Sudan. \\ 3 Jazan University, KSA. On Leave from Sudan University of Science and Technology, Khartoum, Sudan.
}

\begin{abstract}
This paper deals with the step-by-step retrofitting of buildings by using steel plate shear walls (SPSWs) with the aid of SAP2000 programme. One type of reinforced concrete building is selected for evaluation. This building represents the most used forms of residential buildings in the Sudan, in terms of geometric form, and dimensions. This paper uses the equivalent static method provided in the regulations proposed by the Egyptian Society for Earthquake Engineering. One typical model was selected from the existing residual buildings in Khartoum city, as a case study. The proposed methodology that has been used to evaluate the seismic resistance of chosen building is done through the design of the structural elements of the buildings before and after adding the seismic forces. The retrofitting of building was done by using steel plate shear walls with thicknesses of $5 \mathrm{~mm}, 7 \mathrm{~mm}$ and $10 \mathrm{~mm}$. From the results obtained, it was found that the use of two additional SPSWs with $7 \mathrm{~mm}$ thickness placed at the internal frame of the existing system, resulted in a reduction of bending moments in the columns and beams. The increase of thickness has a clear effect on the bending moment of the columns, but has little effects on the bending moments of the beams.
\end{abstract}

Keywords- Retrofitting, SAP2000, Steel Plate Shear Walls (SPSWs), the Sudan

\section{Introduction}

This paper discusses Seismic retrofitting of a typical residential building in the Sudan which have been designed and constructed without any seismic provisions. Seismic retrofitting is a modification of the structural and /or non-structural components in a building that aims to improve the building's performance in future earthquakes. Adding structural walls is one of the most common structure-level retrofitting methods to strengthen existing structures. This approach is effective for controlling global lateral drifts and for reducing damage in frame members. In this paper the seismic retrofitting of existing reinforced concrete RC buildings by means of steel shear walls is examined.

\subsection{The main function of steel plate shear walls}

The main function of a steel plate shear wall (SPSW) is to resist horizontal story shear and overturning moment due to lateral loads. In general, steel plate shear wall system consists of a steel plate wall, two boundary columns and horizontal floor beams, fig.1, and 2 show samples of steel plate shear wall systems [1].

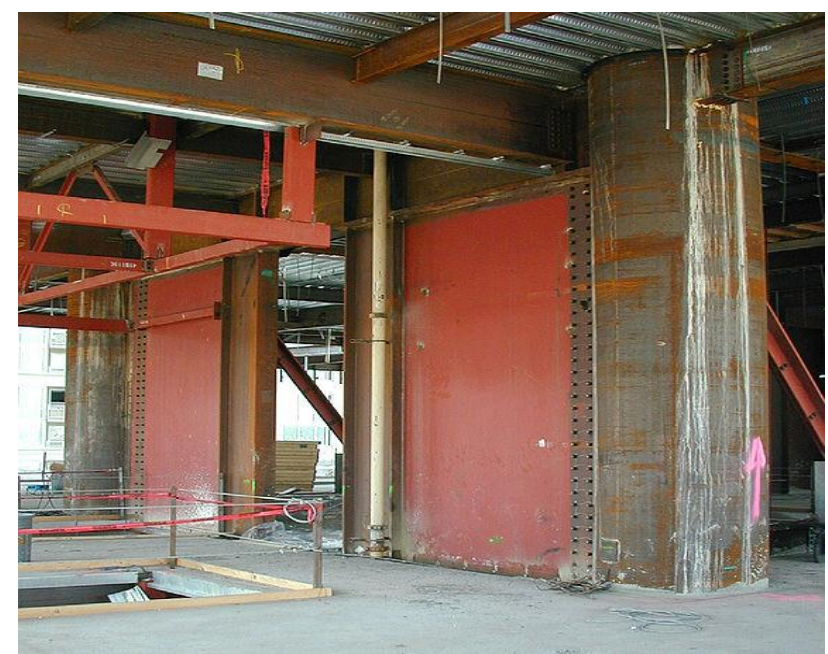

Figure 1. Coupled steel plate shear wall [1] 


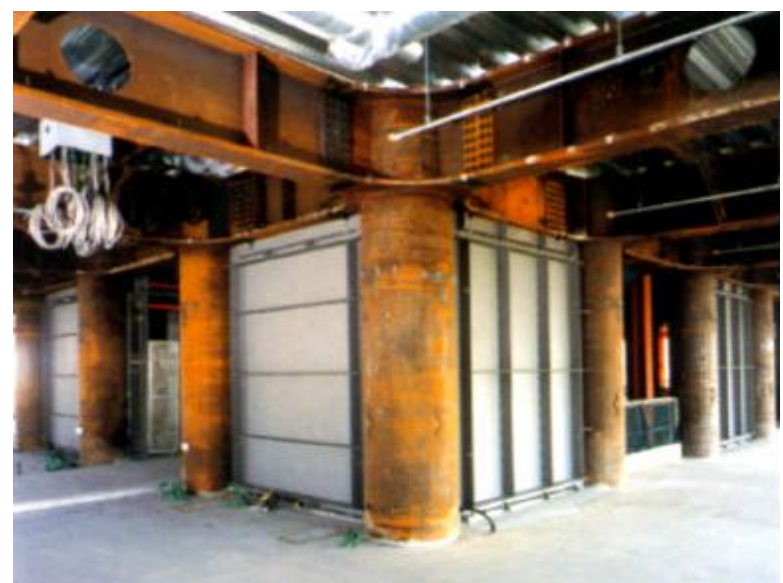

Figure 2. A view of building with steel plate shear walls and a close-up of the walls [1]

\subsection{The construction of steel plate shear walls}

el plate shear wall systems that can be constructed with shop welded-field bolted elements can make Ste the steel plate shear walls more efficient than the traditional systems Fig .3 show the Steel Frame - RC Structure Connections .

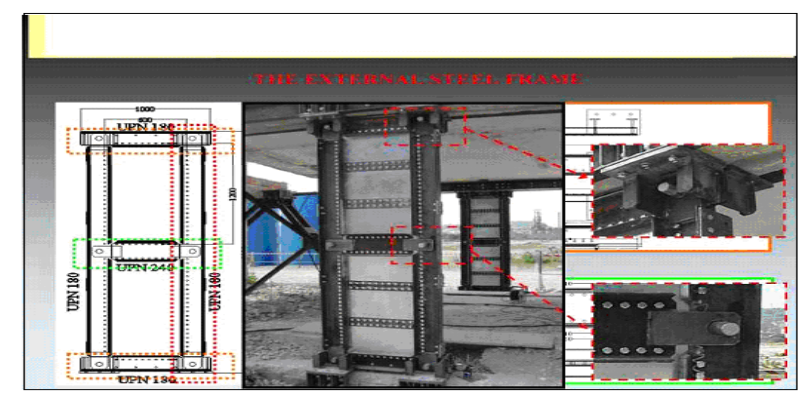

(a)

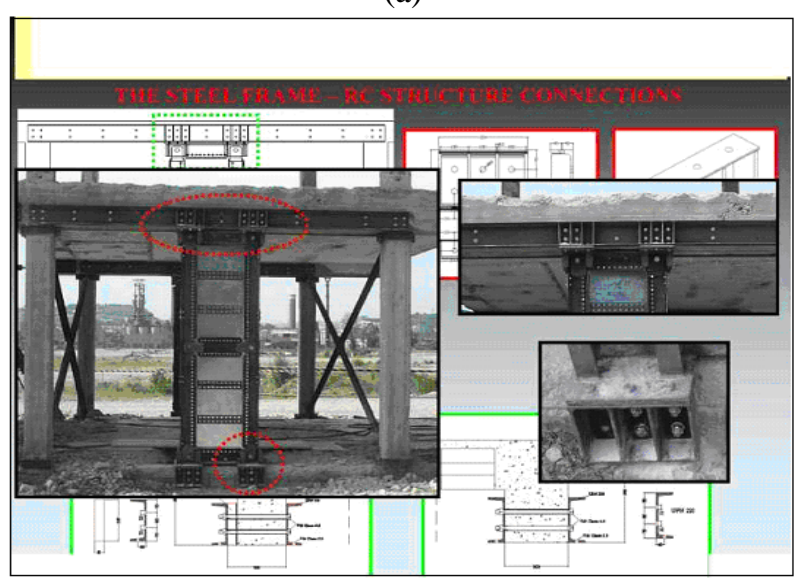

(b)

Figure 3. The steel frame - RC structure connections [2]

\subsection{Description of the Building}

\section{Case Study}

A three-story RC residential building, representing the majority of domestic buildings in Sudan, was selected for this research. The studied frame is an existing building located in Khartoum city zone 2A [8]. The structure system is a moment resisting RC frame with a $200 \mathrm{~mm}$ thickness flat slab, situated .The analysis is carried out using SAP2000 FEA programm [3]. The structural members are made of in-situ reinforced concrete .The overall plan dimension is $18 \mathrm{mx} 24 \mathrm{~m}$. the height of the building is $9.6 \mathrm{~m}$. The rectangular shape was used for the columns. Columns and beams sizes along the building height are listed in Tables 1 and 2.Figs. 4, 5, and 6 show detailed information on the structural and architectural layout of the building. 


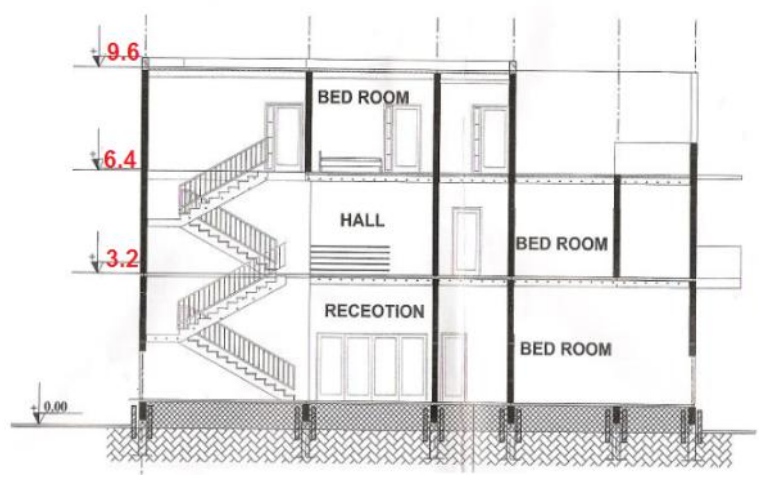

Figure 4. Section $x-x$

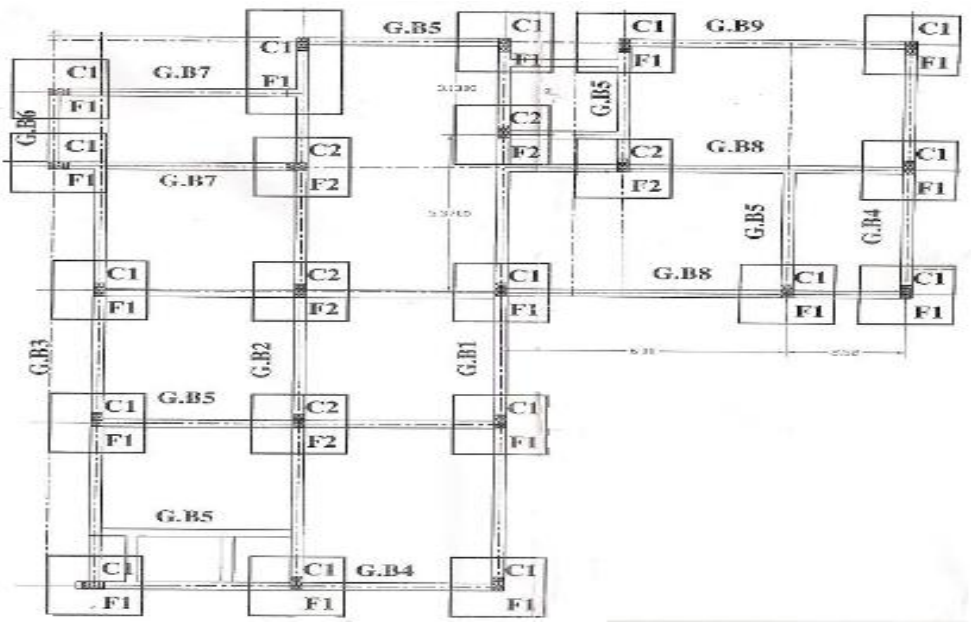

Figure 5.Foundations and columns plan

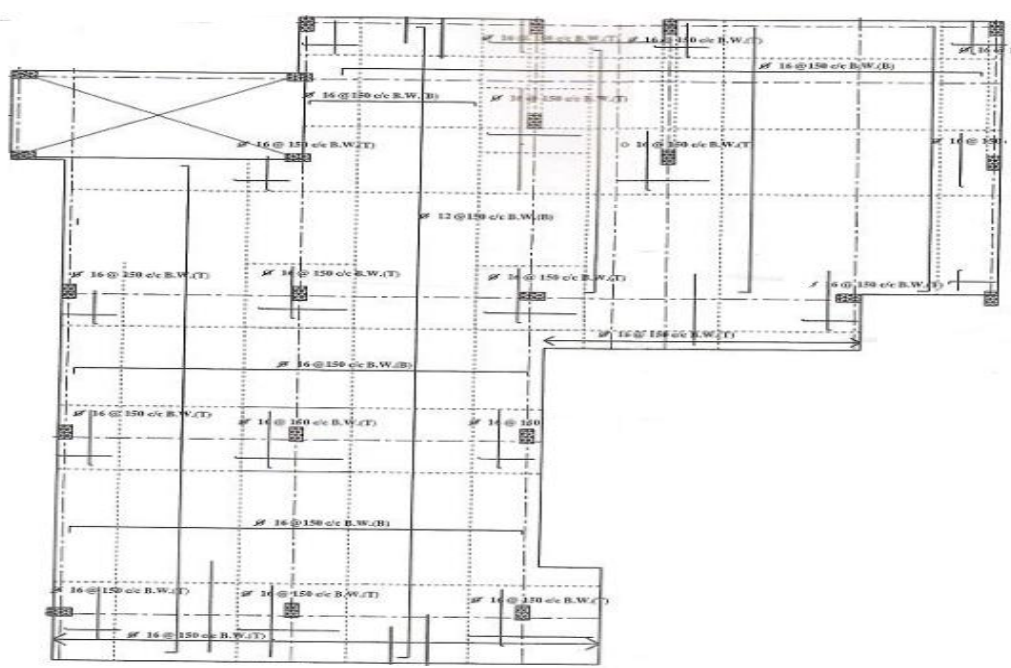

Figure 6. Plan of residual building considered

Table 1. The cross sections of columns

\begin{tabular}{ll}
\hline Story No. & The cross sections of columns \\
\hline Ground floor & $250 \times 500$ \\
\hline First floor & $250 \times 500$ \\
\hline Second floor & $250 \times 500$ \\
\hline
\end{tabular}


Table 2. The cross sections of beams

\begin{tabular}{ll}
\hline Story No. & The cross sections of beams \\
\hline Ground floor & $300 \times 500$ \\
\hline First floor & $300 \times 500$ \\
\hline Second floor & $300 \times 500$ \\
\hline
\end{tabular}

\section{Structural Modeling}

Numerical models for the case has been prepared using SAP2000 version 14 (Computers and Structures) [3]. Beams and columns are modeled as frame elements while walls and slabs are modeled as shell elements. In this paper the seismic performance of the considered residual building will be evaluated using the linear static analysis procedure. .Fig. 7 shows the models for the three-story building. The label of columns is shown in Fig. 8.

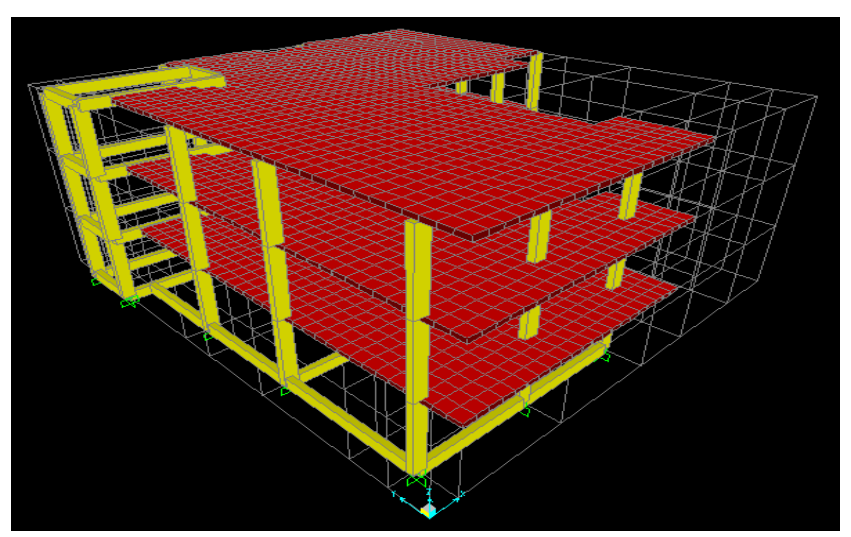

Figure 7. Three-dimension view of the initial structure.

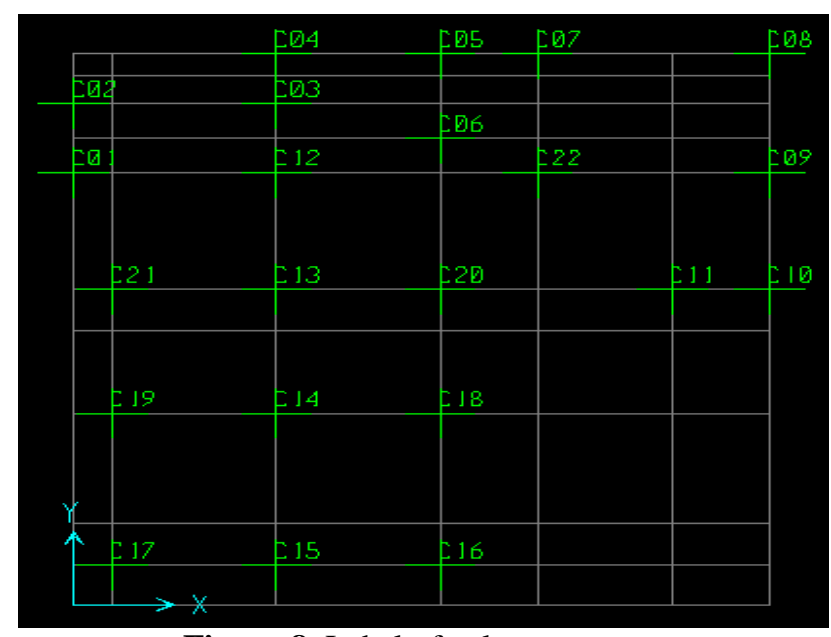

Figure 8. Label of columns

\subsection{Modeling of steel shear walls in Analysis}

The steel plate shear walls can be modeled using full shell elements and isotropic material. It is suggested that the wall panel be modeled using at least 16 shell elements ( $4 \times 4$ mesh) per panel [11]. The lateral force resisting system consists of moment resisting frames with steel plate shear walls. The thickness of steel shear wall panels is taken variable between $5 \mathrm{~mm}-10 \mathrm{~mm}$ [4].

\section{Analysis of Original Building}

The internal forces obtained from the computer analysis program SAP2000 [3] are used to design the reinforced concrete sections of the structural elements of the residual building using the (BS 8110, 1997) [5] ,and the limit state design method (Mosley and Bungey, 1997) [6]. It has been found that the existing design of columns under the effect of gravity loads is adequate for the study case. As for the design of columns a computer program called ISACOL (Shehata, 1999) [7] has been used. The paper studied four columns for the evaluation. Table 3 shows the Straining action for the four columns due to gravity load and Table 4 shows the present design compared with the original design of critical columns for the studied case. It is clear that the 
original design of these columns exceeds the present design which means that it is satisfactory for gravity loads. It is worthy to mention that internal forces in beams of the study case have been calculated under gravity loads. Then the (BS 8110, 1997) [5] has been used to check the existing design. It has been found that the existing design is adequate for the case.

Table 3.Straining action for the four columns due to gravity loads

Where :

\begin{tabular}{lllll}
\hline $\begin{array}{c}\text { Columns } \\
\text { No. }\end{array}$ & Load Case & $\mathrm{N}$ & $\mathrm{Mx}$ & $\mathrm{My}$ \\
\hline $\mathrm{C} 12$ & ULTIMATE & 904.74 & 9.40 & 47.73 \\
\hline $\mathrm{C} 20$ & ULTIMATE & 1181.41 & 2.39 & -9.22 \\
\hline $\mathrm{C} 14$ & ULTIMATE & 1357.83 & 1.07 & -2.03 \\
\hline $\mathrm{C} 22$ & ULTIMATE & 1358.37 & 8.83 & 1.55 \\
\hline
\end{tabular}

$\mathrm{N}$ : is the axial load in the column due to due to forces.

$\mathrm{Mx}$ : is the bending moment at the column due to forces applied in $\mathrm{x}$-direction .

$\mathrm{My}$ : is the bending moment at the column due to forces applied in $\mathrm{y}$ - direction.

5.1 Design of some columns due to gravity loads only (C22):

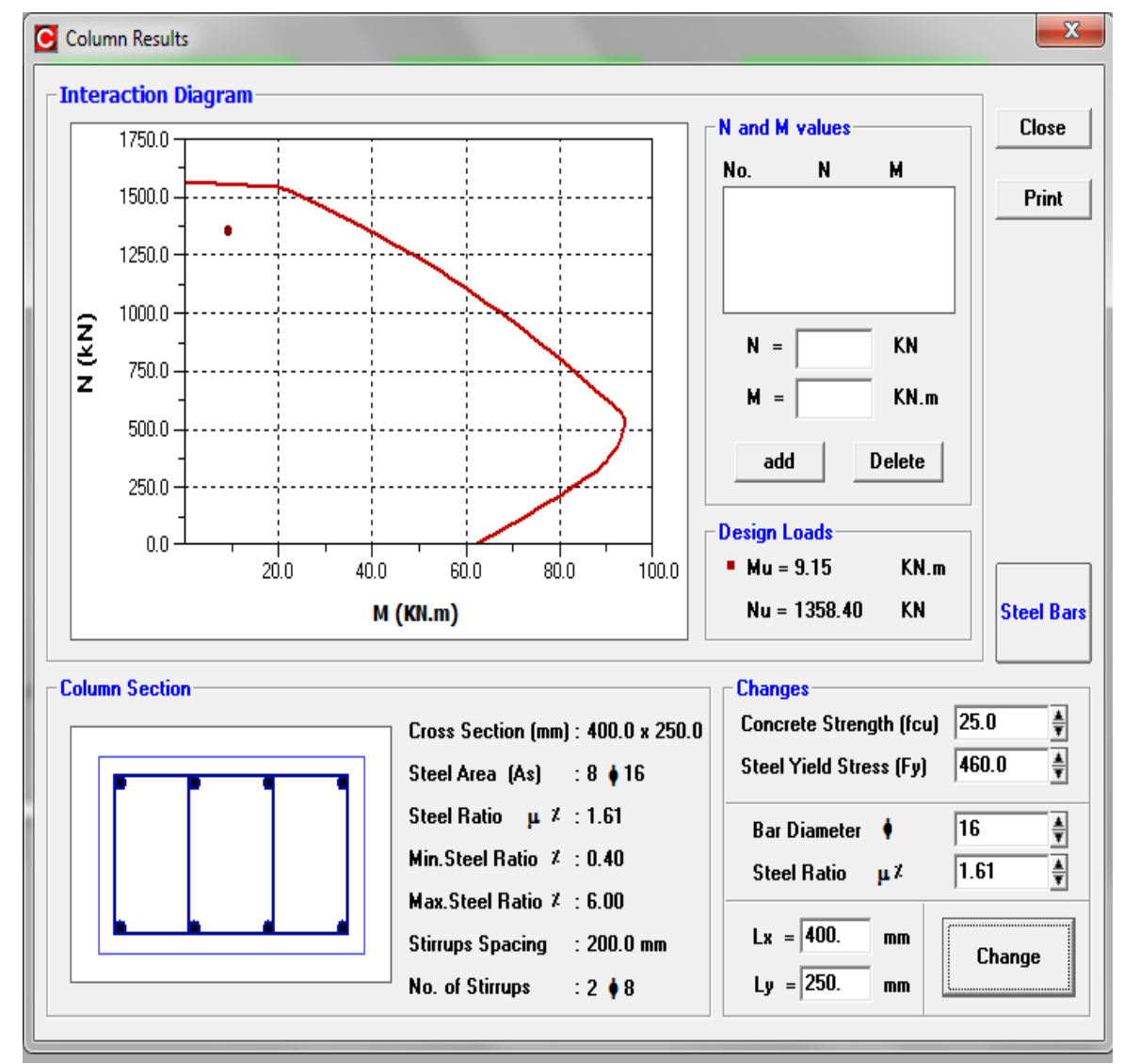

Figure 9. ISACOL Program result for design of column No, C22 due to gravity loads

Table 4. Comparison between original and present design for gravity loads

\begin{tabular}{lllll}
\hline \multirow{2}{*}{$\begin{array}{c}\text { Column } \\
\text { No. }\end{array}$} & \multicolumn{2}{l}{ Original Design } & \multicolumn{2}{l}{ Present Design } \\
\cline { 2 - 5 } & Section* & Reinf. & Section* & Reinf. \\
\hline C12 & $250 \times 500$ & $8 \Phi 16$ & $250 \times 400$ & $8 \Phi 16$ \\
\hline C20 & $250 \times 500$ & $8 \Phi 16$ & $250 \times 400$ & $8 \Phi 16$ \\
\hline C14 & $250 \times 500$ & $8 \Phi 16$ & $250 \times 400$ & $8 \Phi 16$ \\
\hline C22 & 250x500 & $8 \Phi 16$ & $250 \times 400$ & $8 \Phi 16$ \\
\hline \multicolumn{5}{c}{ Section dimensions are in mm. }
\end{tabular}




\section{Check of Design Considering Earthquake and Wind Loads}

The moments obtained from earthquake and wind loads are shown in .Tables4 and 5. It has been found that the effect of seismic load is much more than the effect of wind load. Fig. 12 and fig. 13 show the comparison between moments in columns due to earthquake and wind loads.

\subsection{Wind loads}

The British Standard Code gives methods for determining the gust peak wind loads on buildings and components thereof that should be taken into account in design using equivalent static procedures. Wind loads according to British Standard Code (BSI) were calculated by using SAP2000, and Wind speed factors according to BSI, cp3: chapter V: part 2: 1972 [4] .The basic wind speed V for Khartoum is given by $44.4 \mathrm{~m} / \mathrm{sec}$ [8] .

Table 5. The Staining actions (Mx) due to Wind loads (ENVWX) and Seismic loads (ENVEQX)

\begin{tabular}{lll}
\hline Column & Wind-ENVWX & Seismic-ENVEQX \\
\cline { 2 - 3 } No. & $\mathrm{Mx}$ & $\mathrm{Mx}$ \\
\hline C12 & 9.40 & 9.40 \\
\hline C20 & 4.26 & 2.47 \\
\hline C14 & 1.09 & 1.09 \\
\hline C22 & 11.78 & 8.84 \\
\hline
\end{tabular}

Table 6. The Staining actions (My) due to Wind loads (ENVWX) and Seismic loads (ENVEQX)

\begin{tabular}{lll}
\hline \multirow{2}{*}{ Column No. } & Wind-ENVWX & Seismic-ENVEQX \\
\cline { 2 - 3 } & My & My \\
\hline C12 & 47.63 & 47.63 \\
\hline C20 & -9.26 & -9.26 \\
\hline C14 & -2.00 & -2.00 \\
\hline C22 & 1.52 & 1.52 \\
\hline
\end{tabular}

Table 7. The Staining actions (Mx) due to Wind loads (ENVWY) and Seismic loads (ENVEQY)

\begin{tabular}{lll}
\hline \multirow{2}{*}{ Column No. } & Wind-ENVWY & Seismic-ENVEQY \\
\cline { 2 - 3 } & $\mathrm{Mx}$ & $\mathrm{Mx}$ \\
\hline $\mathrm{C} 12$ & 43.77 & 83.43 \\
\hline $\mathrm{C} 20$ & 34.46 & 71.64 \\
\hline $\mathrm{C} 14$ & 30.88 & 66.33 \\
\hline $\mathrm{C} 22$ & 41.80 & 80.28 \\
\hline
\end{tabular}

Table 8. The Staining actions (MY) due to Wind loads (ENVWY) and Seismic loads (ENVEQY)

\begin{tabular}{lll}
\hline Column & Wind+ENVWY & Seismic+ENVEQY \\
\cline { 2 - 3 } No. & My & My \\
\hline C12 & 51.80 & 50.51 \\
\hline C20 & -8.97 & -9.26 \\
\hline C14 & -2.00 & -2.00 \\
\hline C22 & 4.91 & 13.74 \\
\hline
\end{tabular}

Where, ENVEQX are envelope of Load Combination for seismic loads in direction $\mathrm{x}$, ENVEQY: are envelope of Load Combination for seismic loads in direction in direction Y.

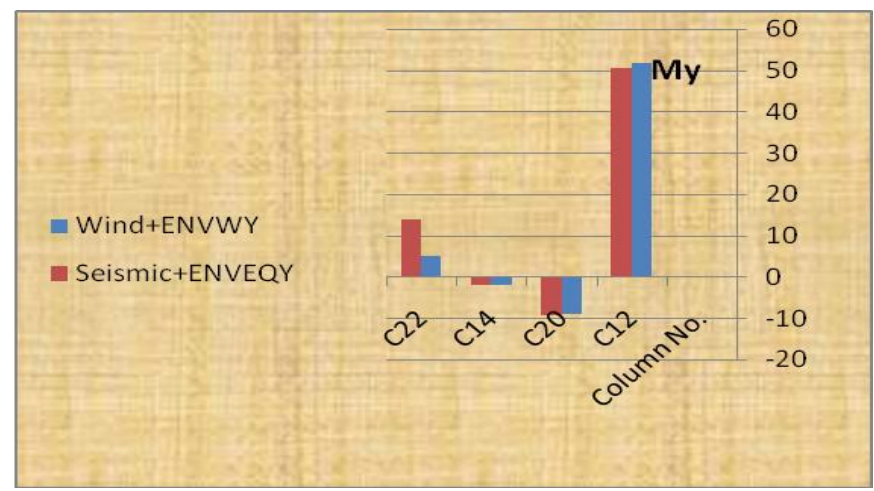

Figure 10.Comparison between My due to Wind loads and My due to Seismic loads 


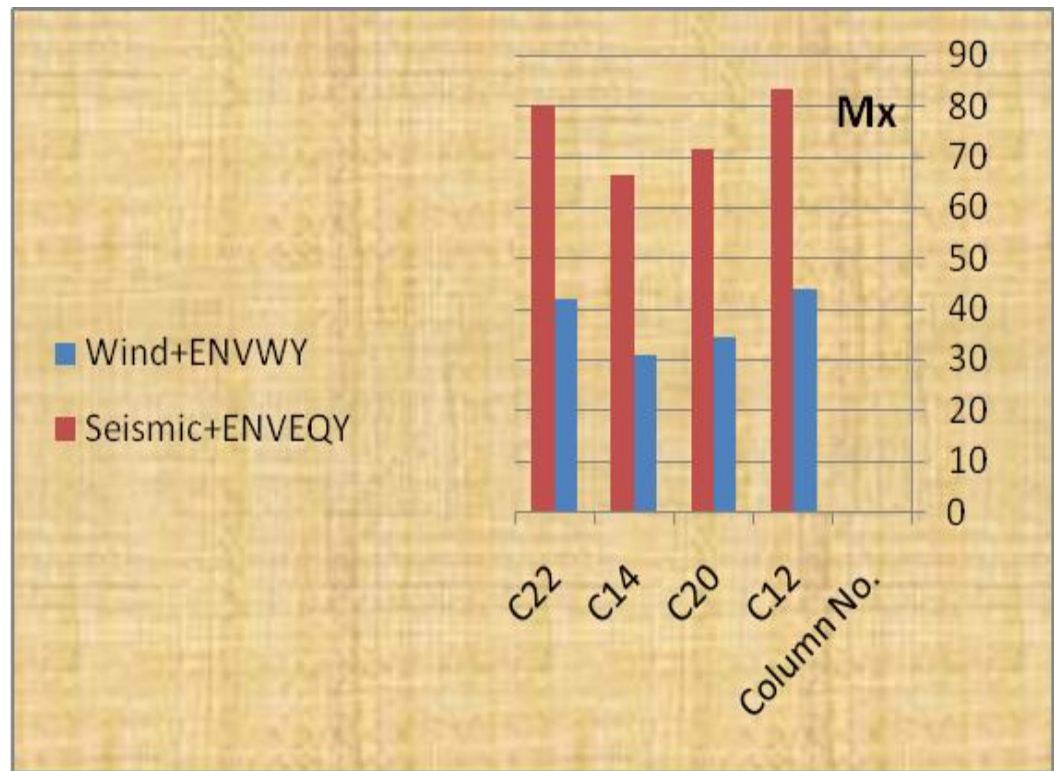

Figure 11.Comparison between Mx due to Wind loads and Mx due to Seismic loads loads only

In all directions the effect of seismic loads is govern so, the paper concentrated in the effect of seismic

\subsection{Earthquake loads}

It is well known that the Sudan has no regulations for the seismic design of buildings. Therefore, in the present paper earthquake loads are calculated following the rules which are given in the Regulations for earthquake resistant design of buildings in Egypt, (ESEE, 1988) [9]. These regulations have been prepared by the Egyptian Society for Earthquake Engineering (ESEE). In order to apply the ESEE regulations a seismic map for the Sudan is required to determine the site seismicity factor. In 2002, Eissa et al . Developed a new seismic hazard maps and seismic zoning map for the Sudan (Eissa et al , 2002) [8] , as shown in Fig.12.

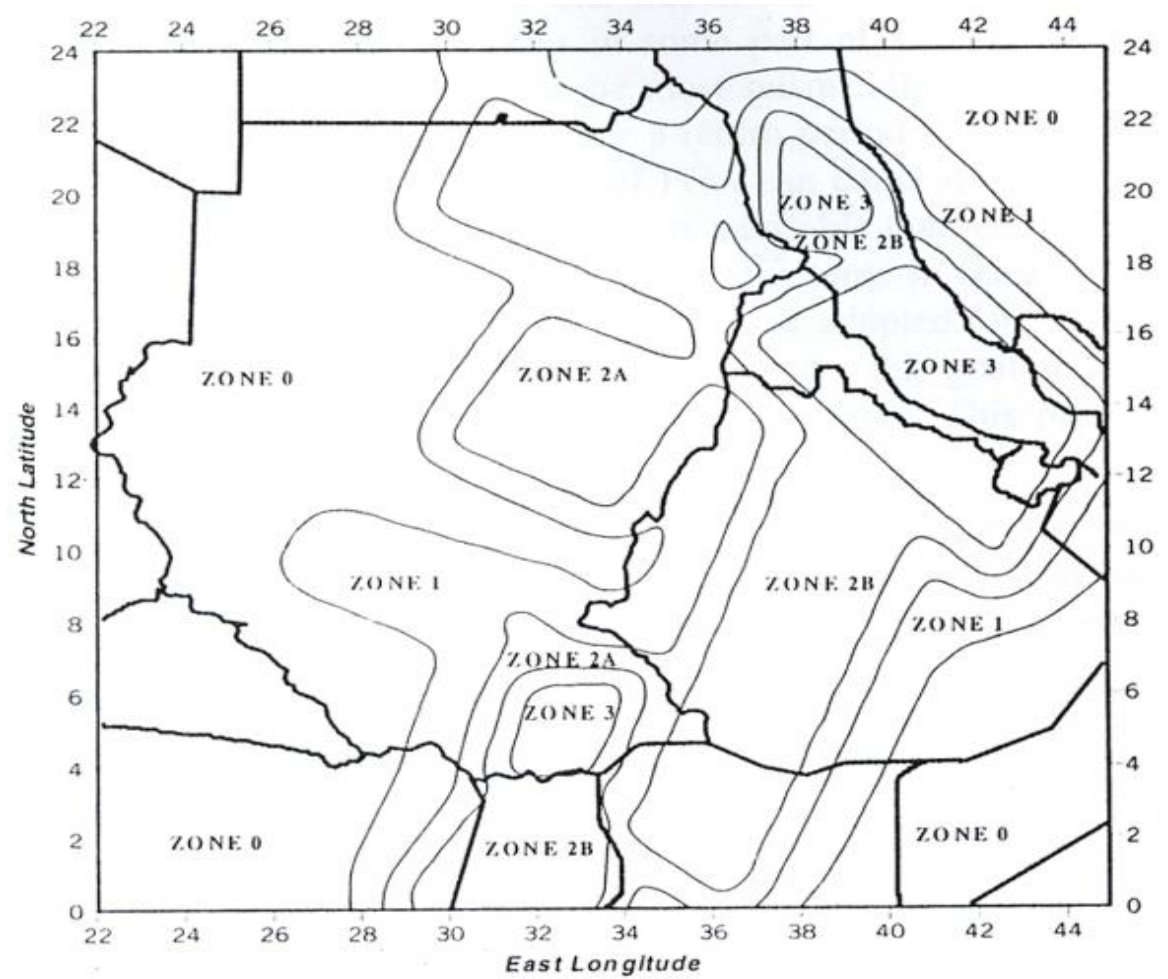

Figure 12. Seismic Zoning Map of the Sudan (Eissa et al , 2002) [8] 


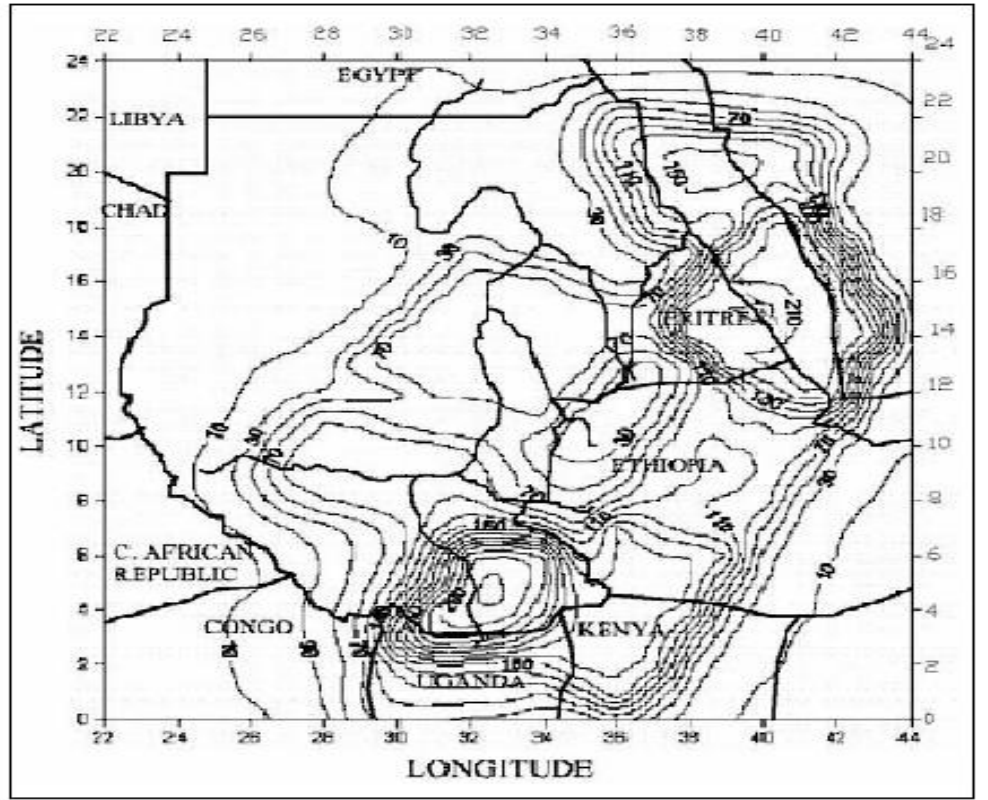

Figure 13. Seismic Hazard Map of the Sudan (Hassaballa et al , 2010) [10].

\section{Seismic Assessment by the ESEE. 1988}

The total design seismic base shear force is estimated using the static equivalent force procedure (ESEE, 19880) [9]. Four our case study, distribution of the lateral seismic loads is shown in fig 16 , for both directions.

\subsection{Calculation of base shear}

The total weight is given by equation (1) :

$$
\mathrm{Wi}=\mathrm{Di}+\mathrm{PLi}
$$

Where, $p$ is the incidence factor and is equal to $\mathrm{p}=0.25$. After analysis for gravity loads, the total floor weight will be as follows: $8955 \mathrm{KN}$.The equivalent lateral force procedure of (ESEE 1988) was used to calculate the design base shear. The resulting seismic coefficient, Cs, was determined to be 0.125 and the corresponding base shear was approximately $1120 \mathrm{KN}$.from equation (2):

$$
\mathrm{V}=\mathrm{Cs} * \mathrm{Wt}
$$

\subsection{Distribution of horizontal seismic force}

The period of the building is the same in both directions. Hence, the load in the E-W direction are the same as those for the N-S direction as shown Fig 14.

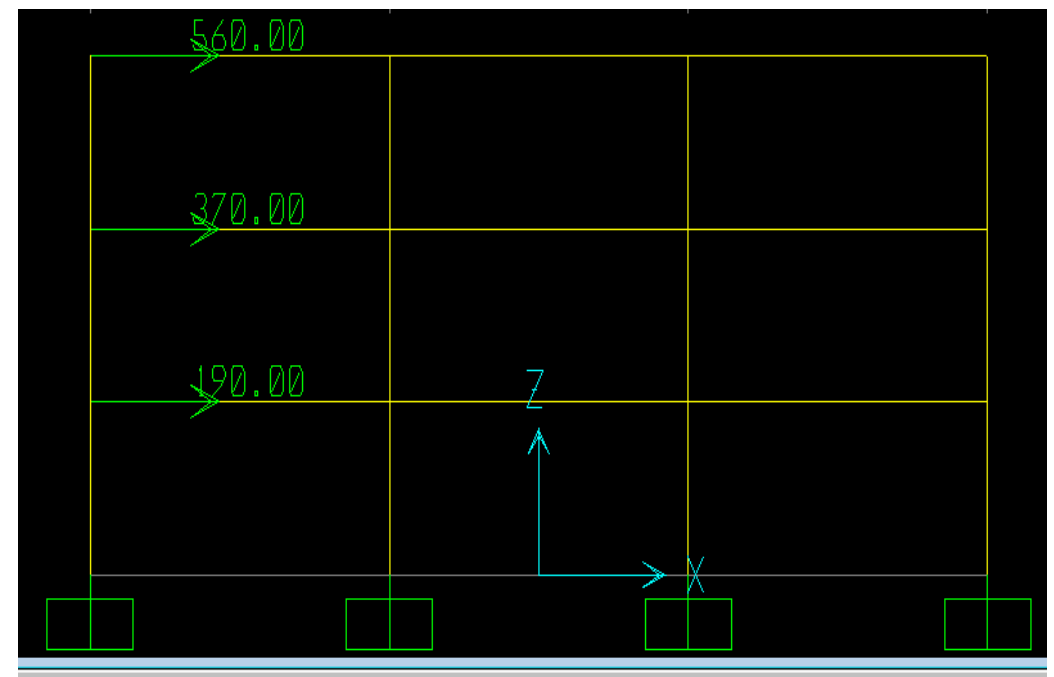

Figure 14.Distribution of horizontal seismic force 


\subsection{Check of seismic design for study case}

Numerical analysis for the study case has been performed using SAP2000 (Computers and Structures) [3] and the reinforced concrete columns are designed according to the (BS 8110, 1997) [5] using the limit state design method (Mosley and Bungey, 1997) [6].Table 9 and 10 show the Straining action (moments) for the ten columns due to seismic load, and the seismic design compared with the original design of that columns which are chosen respectively. It is clear that most of columns are unsafe due to seismic loads. Therefore, a strengthening scheme is needed for the residual building in order to resist earthquake forces.

Table 9.Straining action for the same four columns due to seismic loads

\begin{tabular}{lllll}
\hline Column No. & Load Case & $\mathrm{N}$ & $\mathrm{Mx}$ & $\mathrm{My}$ \\
\hline $\mathrm{C} 12$ & ENVEQY & 904.60 & 83.43 & 50.51 \\
\hline $\mathrm{C} 20$ & ENVEQY & 1181.39 & 71.64 & -9.26 \\
\hline C14 & ENVEQY & 1357.73 & 66.33 & -2.00 \\
\hline C22 & ENVEQY & 1358.28 & 80.28 & 13.74 \\
\hline
\end{tabular}

\subsubsection{Design of some columns due to gravity and seismic loads (C22):}

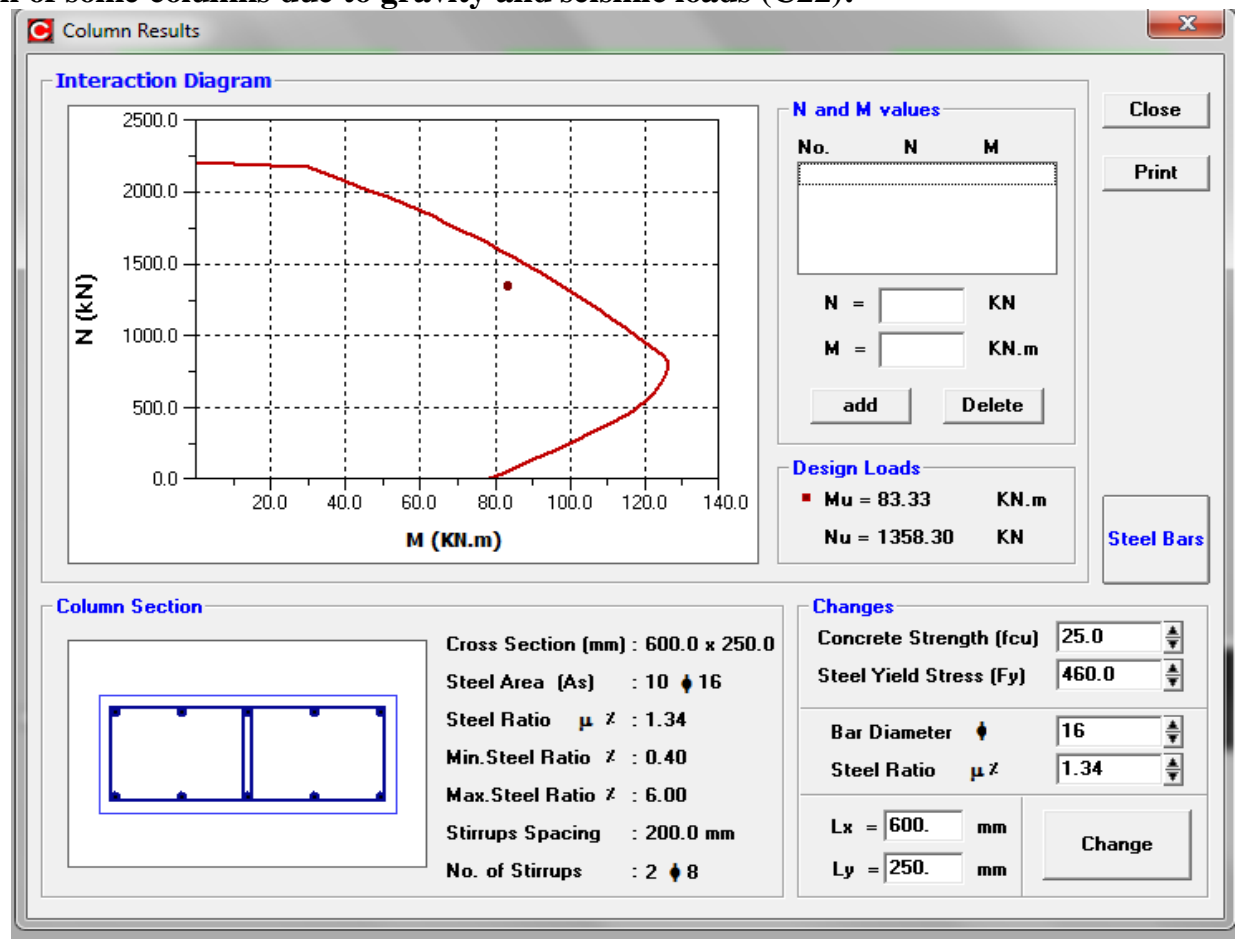

Figure 15.ISACOL Program result for Design of Column No, C22due to seismic loads

Table 10. Comparison between Original and Present Design Including Seismic Loads

\begin{tabular}{lllll}
\hline \multirow{2}{*}{$\begin{array}{c}\text { Column } \\
\text { No. }\end{array}$} & \multicolumn{2}{c}{ Original Design } & \multicolumn{2}{c}{ Present Design } \\
\cline { 2 - 5 } & Section* & Reinf. & Section* & Reinf. \\
\hline C12 & $250 \times 500$ & $8 \Phi 16$ & $250 \times 550$ & $10 \Phi 16$ \\
\hline C20 & $250 \times 500$ & $8 \Phi 16$ & $250 \times 500$ & $10 \Phi 16$ \\
\hline C14 & $250 \times 500$ & $8 \Phi 16$ & $250 \times 500$ & $10 \Phi 16$ \\
\hline C22 & $250 \times 500$ & $8 \Phi 16$ & $250 \times 600$ & $10 \Phi 16$ \\
\hline & * Section dimensions are in mm.
\end{tabular}

\section{Suggesting of Retrofitting}

\subsection{Type of retrofitting}

There are many seismic retrofit techniques available, depending on the purpose needed from strengthening, types and conditions of structures. Seismic retrofitting is the modification of existing structures to make them more resistant to seismic ground motion, or soil failure due to earthquakes .

There are two ways to enhance the seismic capacity of existing structures. The first approach is a structure-level retrofit, which involves global modifications to the structural system. Common global modifications include the addition of structural walls, steel braces, or base isolators. The second approach is a member-level retrofit. In this approach, the ductility of components with inadequate capacities is increased to satisfy their specific limit 
states. The member-level retrofit includes methods such as the addition of concrete, steel, or fiber reinforced polymer (FRP) jackets to columns for confinement [11] .Fig. 16-18 show some technique using to retrofit existing structures.

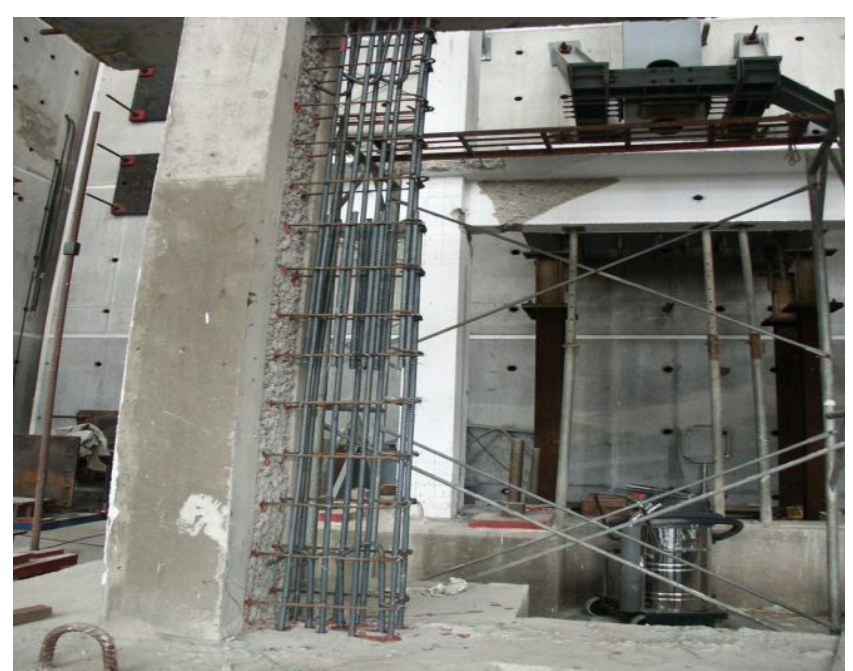

Figure 16. Retrofitted with RC Wing Wall

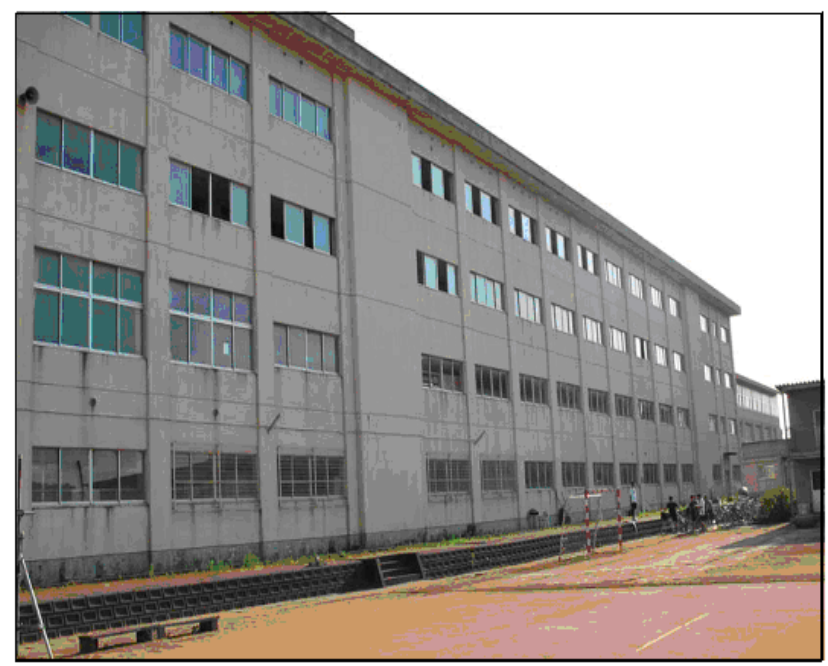

Figure 17. School building retrofitted with shear walls

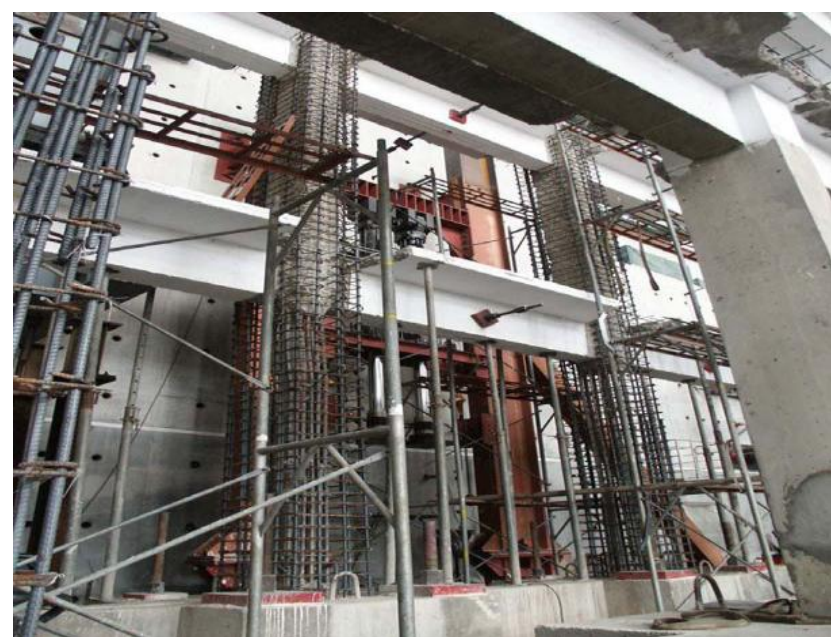

Figure 18. Retrofitting with RC Column Jacketing [12] 


\section{2 suggestion of strengthening}

There are different methods for seismic strengthening of existing buildings. However, social and economic conditions should be considered to choose the appropriate method. Adding structural walls is one of the most common structure-level retrofitting methods to strengthen existing structures. This approach is effective for controlling global lateral drifts and for reducing damage in frame members [5]. Structural walls may be either reinforced concrete or steel plate. In this paper new SPSWs with $5 \mathrm{~mm}, 7 \mathrm{~mm}$, and $10 \mathrm{~mm}$ thickness were added in (y) direction along the height of the structure. Fig. 20, 21 , and 22 show the suggested strengthening of the structure with the new SPSWs.

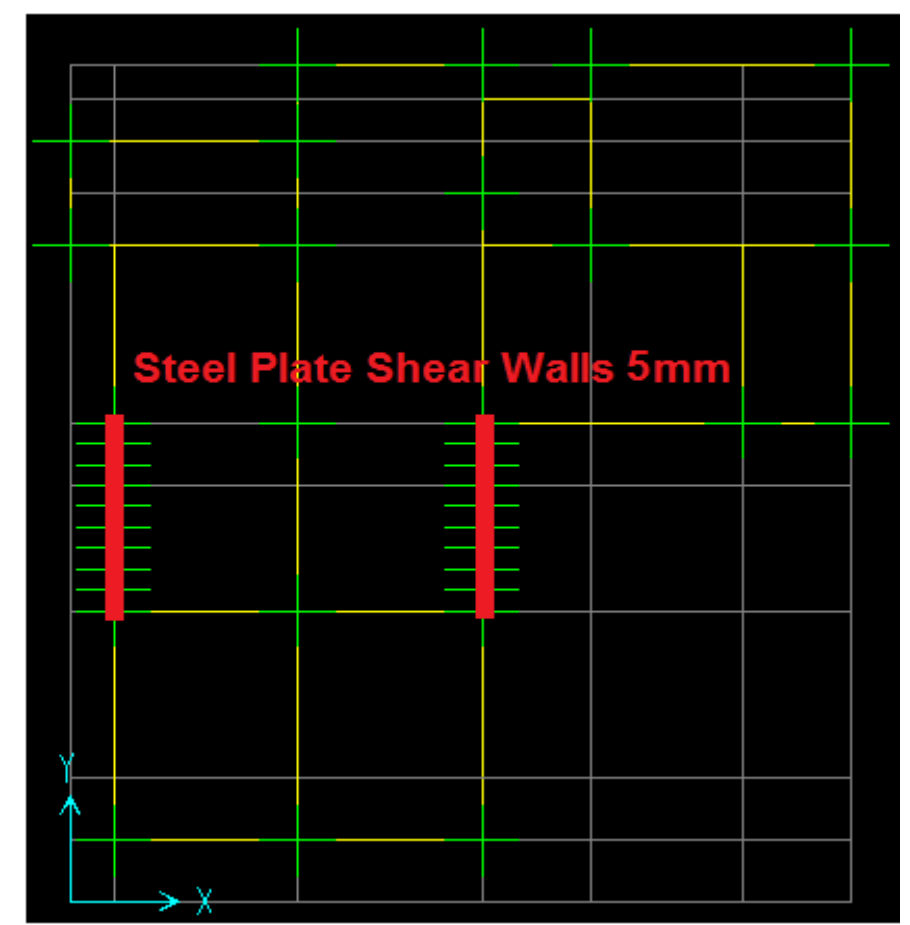

Figure 20. The SPSWs $5 \mathrm{~mm}$

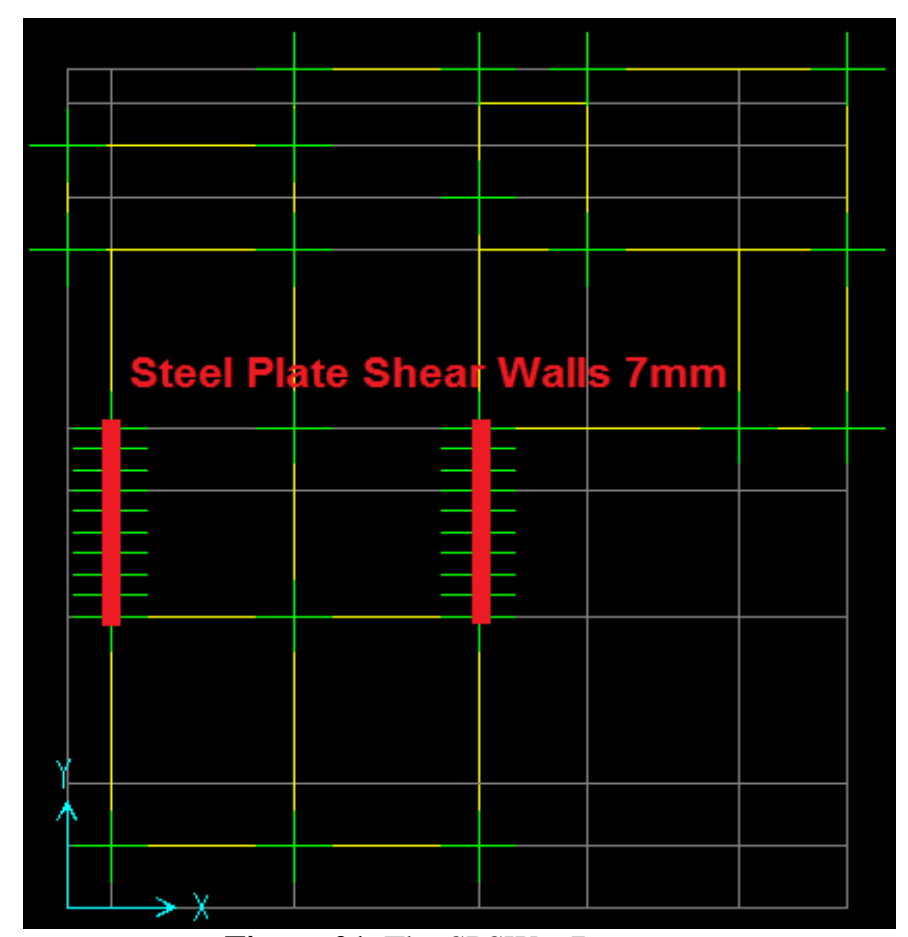

Figure 21. The SPSWs $7 \mathrm{~mm}$ 


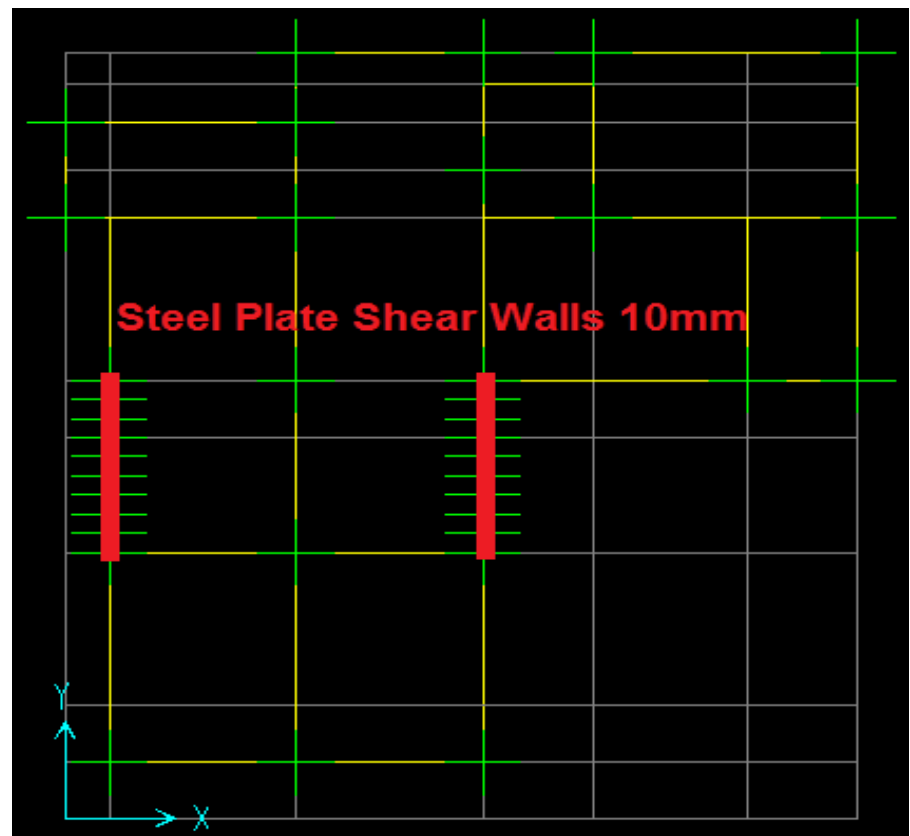

Figure 22. The SPSWs $10 \mathrm{~mm}$

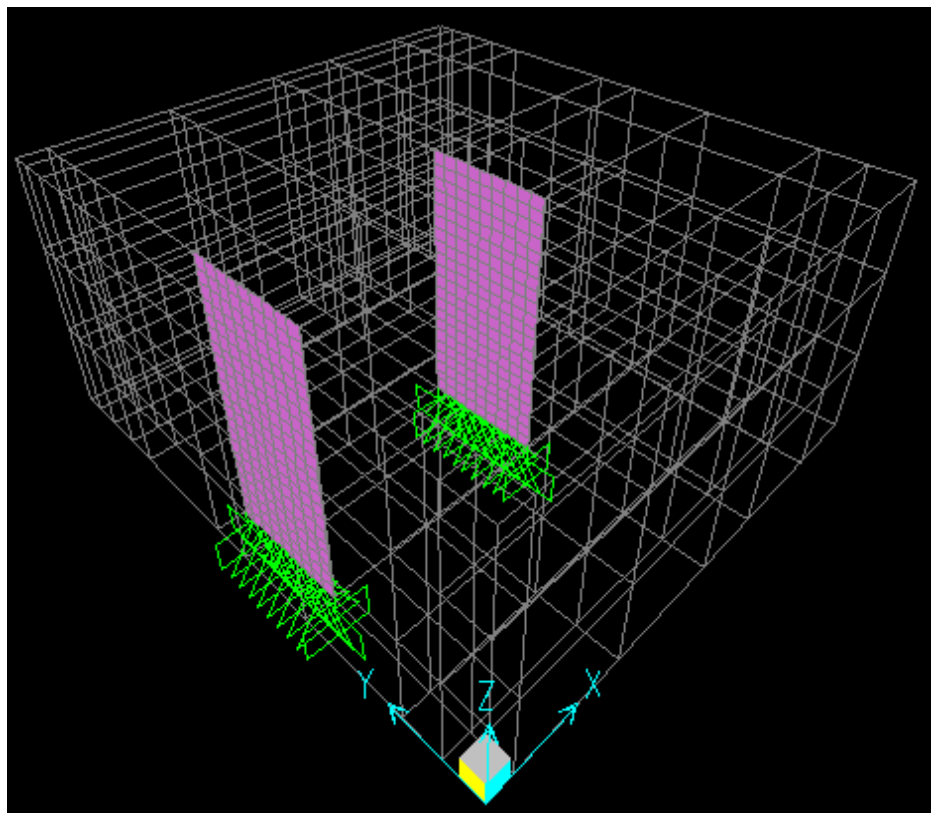

Figure 23. Modeling of shear wall in y directions [14]

\section{Analysis of Retrofitted Structure}

The strengthened structure was reanalyzed using the same procedure. The proposed method increased the performance of the structure in both directions either for strength, displacement and ductility capacity. Table. 11 show straining action for the four columns that which is chosen due to seismic load before and after strengthening. It has been found that all columns in the study case became safe after strengthening.

Table 11. Straining action for the four columns that which are chosen due to seismic load before and after strengthening.

\begin{tabular}{clllll}
\hline $\begin{array}{c}\text { Column } \\
\text { No. }\end{array}$ & Gravity & Seismic+Column & $\begin{array}{l}\text { SPSW } \\
5 \mathrm{~mm}\end{array}$ & $\begin{array}{l}\text { SPSW } \\
7 \mathrm{~mm}\end{array}$ & $\begin{array}{l}\text { SPSW } \\
10 \mathrm{~mm}\end{array}$ \\
\hline $\mathrm{C} 12$ & 9.40 & 83.43 & 35.09 & 29.96 & 25.26 \\
\hline $\mathrm{C} 20$ & 2.39 & 71.64 & 56.63 & 53.27 & 49.66 \\
\hline $\mathrm{C} 14$ & 1.07 & 66.33 & 24.94 & 20.50 & 16.41 \\
\hline $\mathrm{C} 22$ & 8.83 & 80.28 & 41.19 & 36.46 & 31.86 \\
\hline
\end{tabular}




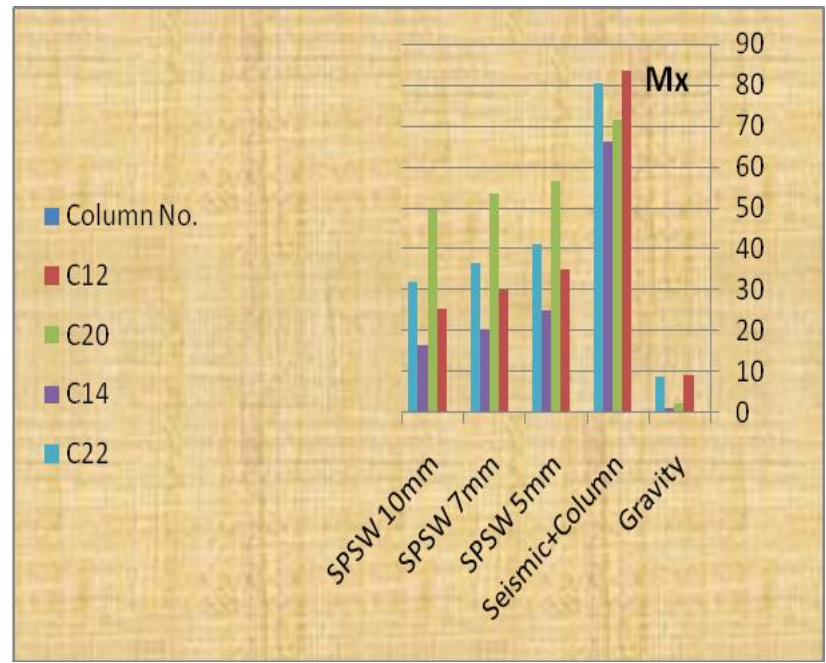

Figure 24.Straining action Mx for the four columns which are chosen due to seismic load before and after strengthening.

Table 12. Straining action My for the four columns that which are chosen due to seismic load before and after strengthening.

\begin{tabular}{llllll}
\hline $\begin{array}{l}\text { Columns } \\
\text { No. }\end{array}$ & Gravity & Seismic+Column & SPSW 5mm & SPSW 7mm & $\begin{array}{l}\text { SPSW } \\
10 \mathrm{~mm}\end{array}$ \\
\cline { 2 - 6 } & My & My & My & My & My \\
\hline C12 & 47.73 & 50.51 & 54.24 & 53.83 & 53.06 \\
\hline C20 & -9.22 & -9.26 & -9.68 & -9.74 & -9.80 \\
\hline C14 & -2.03 & -2.00 & -2.75 & -2.88 & -3.01 \\
\hline C22 & 1.55 & 13.74 & 15.87 & 15.39 & 14.61 \\
\hline
\end{tabular}

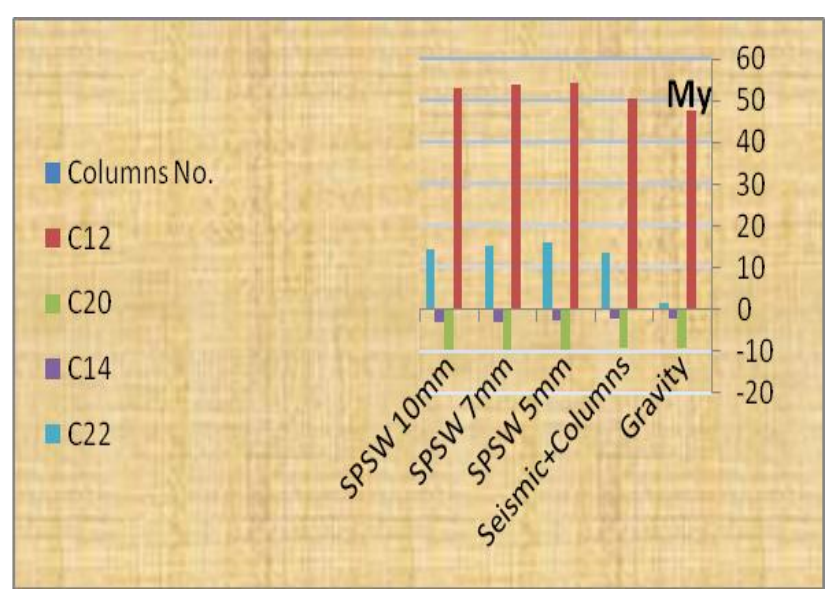

Figure 25.Straining action My for the four columns which are chosen due to seismic load before and after strengthening.

Table 13. Comparison between Original and Strengthened Design for Study Case .

\begin{tabular}{lllll}
\hline \multirow{2}{*}{ Column No. } & \multicolumn{2}{l}{ Original Design } & \multicolumn{2}{l}{ After Strengthening } \\
\cline { 2 - 5 } & Section* & Reinf. & Section* & Reinf. \\
\hline C12 & $250 \times 500$ & $8 \Phi 16$ & $250 \times 400$ & $8 \Phi 16$ \\
\hline C20 & $250 \times 500$ & $8 \Phi 16$ & $250 \times 400$ & $8 \Phi 16$ \\
\hline C14 & $250 \times 500$ & $8 \Phi 16$ & $250 \times 400$ & $8 \Phi 16$ \\
\hline C22 & $250 \times 500$ & $8 \Phi 16$ & $250 \times 400$ & $8 \Phi 16$ \\
\hline \multicolumn{5}{c}{$*$ Section dimensions are in mm }
\end{tabular}

\section{Conclusion}

One of the most difficult problems of strengthening of existing buildings is how to find the adequate solution that satisfies both economical and technical aspects. 
This study presents guidelines to investigate the seismic resistance of buildings in Sudan.? The present paper proposes a simple procedure to check the seismic resistance and retrofit of such buildings. The obtained results emphasize the following conclusions: (1) Current design of residual buildings in the Sudan does not consider earthquake loads,(2) It has been found that the current design of buildings in the Sudan is not safe for the current seismicity of the Sudan,(3) A proposed methodology has been presented for evaluation of seismic resistance of existing buildings in the Sudan, and (4) A strengthening technique for existing buildings in the Sudan has been presented. (5) with the use of $7 \mathrm{~mm}$ thickness steel plate shear wall inserted in the building, a reduction of bending moments in the columns and beams was observed. (6) The increase of thickness has a clear effect on the bending moment of the columns, and has little effects on the bending moment of the beams.

It is recommended that, since this retrofitting method showed a great improvement in the capacity of the building, it should be adopted as a suitable strategy for this case to reduce the seismic vulnerability of exiting RC buildings in Sudan.

\section{References}

[1]. Abolhassan, P.E. ,Seismic Behaviour and Design of Steel Shear Walls.(ASI, Steel TIPS, First Print, California,2001),

[2]. Astaneh-Asl, A., Steel Plate Shear Walls, Proceedings, U.S.-Japan Partnership for Advanced Steel Structures, U.S.-Japan Workshop on Seismic Fracture issues in Steel Structure, San Francisco,February 2000.

[3]. Computers and Structures. SAP2000: Three Dimensional Static and Dynamic Finite Element Analysis and Design of Structures, Computers and Structures Inc., Berkeley, California, U.S.A. 2001.

[4]. Ismaeil, M. A., and Sobaih, M.E, A Proposed Methodology for Seismic Evaluation and Strengthening of Existing School Buildings in The Sudan., 15th WCEE, Portugal, September, 2012. Paper No.0 571.

[5]. BS 8110. The Structural Use of Concrete, British Standard Institution, London. 1997.

[6]. Mosley, W. H. and Bungey, J. H. ,Reinforced Concrete Design (BS 8110:Part 1, 2nd Ed. Macmillan, London. 1997).

[7]. A .Y. Shehata, Information Systems Application on Reinforced Concrete Columns., M.Sc. Thesis, Faculty of Engineering, Department of Structural Engineering, Cairo University, Giza, Egypt, 1999.

[8]. A .A. Eissa, Towards a Sudanese Code of Practice for Earthquake Design., M.Sc. Thesis., Faculty of Engineering, Department of Structural Engineering, Khartoum University, Khartoum, Sudan. 2002.

[9]. Egyptian Society for Earthquake Engineering (ESEE), Regulations for Earthquake-Resistance Design of Buildings in Egypt.,Cairo ,Egypt.,(1988).

[10]. Hassaballa, A. E , Sobaih, M. E \& A. R. A. Mohamed ,Sensitivity Analysis in Estimating Seismic Hazard for Sudan., Proc., 14th European Conference on Earthquake Engineering, 30 Aug.-3 Sept., 2010, Ohrid, Republic of Macedonia.

[11]. Jong-Wha Bai, Seismic Retrofit for Reinforced Concrete Building Structures , Final Report ,. Consequence-Based Engineering (CBE) Institute,. Texas ,2003.

[12]. Murty .C. V. R ., The Seismic Performance of Reinforced Concrete Frame Buildings with Masonry Infill Walls ,A Tutorial Developed by a Committee of the World Housing Encyclopedia,(First Edition ,Publication Number WHE,2006).

[13]. Sobaih, M. E ;Hassaballa, A. E , \& Ismaeil, M. A. ,Assessment of Seismic Performance and Strengthening of Existing School Buildings in the Sudan, International Journal of Engineering Research \&Technology (IJERT),ISSN:2278-0181, 2 (6), 2013.

[14]. Ismaeil, M. A., and Sobaih, M.E, A Proposed Methodology for Seismic Evaluation and Strengthening of Existing School Buildings in The Sudan., 15th WCEE, Portugal, September, 2012. Paper No.0 571. 